\title{
Prevalence and risk factors leading to orthopedic wound infection at Assiut Hospital University
}

\author{
Neama Hasanin Kotb ${ }^{1}$, Zienab Abd Ellateef Mahammad ${ }^{2}$, Hisham Abdel Rahim El kadey ${ }^{3}$ \& Sahar Ali Abd \\ El-mohsen ${ }^{4}$. \\ 1. B.Sc.Ng, Faculty of Nursing, Assiut University, Egypt. \\ 2. Professor of Medical- Surgical Nursing, Faculty of Nursing, Assiut University Egypt. \\ 3. Professor of Orthopedic Surgery, Faculty of Medicine, Assiut University, Egypt. \\ 4. Lecturer of Medical - Surgical Nursing, Faculty of Nursing, Assiut University, Egypt.
}

\begin{abstract}
Background: Orthopedic wound infection is an infection of the skin and other soft tissue can lead to infection of bones (osteomyelitis) and joints (septic arthritis). Aim of the study is to assess prevalence and risk factors leading to orthopedic wound infection at Assiut Hospital University. Research design a descriptive research design was used to meet the aim of the study. Tools: the following tools were utilized for data collection Tool (I): Patient's interview questionnaire sheet Tool (II): Assessment of risk factors leading to wound infection. Results: Prevalence of orthopedic wound infection at Assiut University Hospital over the past three months from May to July from of the year 2018 was 57 patients out of 200 patients admitted to orthopedic and trauma department, the majority of the studied patients were have anemia (54.5\%), (64\%) of the studied patients received blood transfusion, (19\%) were having diabetes mellitus, the majority of them (97.5\%) received a prophylactic antibiotic, $(21 \%)$ were having menstruation during surgery for females, $(88.5 \%)$ were have closed fracture .Conclusion: Prevalence of orthopedic wound infection at Assiut University Hospital over three months was $(28.5 \%)$, there was a positive correlation between dressing technique and wound infection of the studied sample. Recommendations: Increase the awareness of nurses through attending scientific meeting and conferences and to keep them pace with the rapidly growing wealth of knowledge and practice.
\end{abstract}

\section{Key words: Prevalence, Risk factors \& Orthopedic Wound Infection.}

\section{Introduction}

Orthopedic wound infection is a clinical syndrome caused by invasion and multiplication of invading, disease- producing microorganism in body (Shrestha \& Thapa, 2018).

Incidence rate in orthopedic patients, the surgical site infection prolong hospital stay on average for two weeks, double rehospitalization rates, and costs can increase by $(300 \%)$. In addition, patients may have physical limitations and decreased patient's quality of life (Husebye et al., 2012)

Risk factors of orthopedic wound infections are age, gender, obesity, anemia, malnutrition, tobacco smoking, length of hospital stay, presence of chronic disease, Preoperative hyperglycemia, use of prophylactic antibiotic, skin and surgical preparation, surgical procedure time, type and location of surgery, use of drains, blood transfusion and menstruation during surgery for females (Daines et al., 2015) Manifestations of orthopedic wound infection: fever, pain, swelling, redness in or near a wound, yellow, yellow -green or foul smelling drainage from a wound, change in color or size of a wound, hematoma, dehiscence and pus (Santos et al., 2010) Diagnosis of surgical site infection related to clean orthopedic surgical procedure is a complex process, using clinical signs and symptoms, laboratory data, and radiologic findings (Barrackand Harris, 2013). The main stay of treatment continues to be surgical intervention in combination with antibiotics. Extensive courses of antibiotics are required for periods of weeks to months. The need for these long courses of antibiotics creates several concerns, the most significant of these is the development of antimicrobial resistance (Tong et al., 2015).

Nursing role to prevent infections in skin wounds, the nurse must follow these tips, wear gloves and gowns, wash their hands frequently, keep all foreign matter as (hair, clothing, dirt and fluids) out of the wound, do not try to remove matter embedded in the wound, use sterile materials for the first dressing of the wound, reporting promptly to the attending physician any evidence of infection in patients under the nurse's care, limiting patient exposure to infections from visitors, hospital staff, other patients or equipment, initiating patient isolation and ordering culture specimens from any patient showing signs of a communicable disease (Baron et al., 2013 ).

\section{Significance of the study}

During the last six months of these year (2017), according to Assiut hospital registry (orthopedic department), about 486 patient experienced infection

Vol , (7) No, (17) June, 2019 
in the wound. Orthopedic wound infection leads to prolonged hospital stays, recurrence of hospitalization, and increase health care costs.

\section{Aims of the study}

1. To assess prevalence of orthopedic wound infection.

2. To assess risk factors leading to orthopedic wound infection.

\section{Research question}

What are the prevalence and risk factors leading to orthopedic wound infection?

\section{Subjects \& Methods \\ Research design}

A descriptive research design was used to meet the aims of the study.

\section{Setting}

This study was conducted in the orthopedic and trauma department at Assiut university Hospital.

\section{Sample}

A sample of (200) adult patients their age range between (18-65) years old from both sexes admitted to the orthopedic and trauma department at Assiut University Hospital for a period of 3 months from (May to July) of the year 2018.

\section{Tools of the study}

Two tools were used in this study and were developed by the researcher to collect the necessary data for this study after reviewing national and international literature under guidance of supervisors.

Tool (I): Patient's interview questionnaire sheet (Annex I)

This tool was developed by the researcher to assess patient's condition, it consists of two parts:-

\section{Part (1): Demographic data of the patient:}

It was developed to assess the patient's demographic characteristics as age, gender, date of admission, date of discharge, residence, educational level and occupation.

Part (2): Physical and medical data of the patient: It was developed by the researcher after review of literature aimed to identify patient's health problems (present and past), this part was divided into general and localized assessment as follows:-

A-General physical assessment of the patient:

It included vital signs, weight, height (Body mass index), surgical history (type and date) and family history of diabetes, asthma, chronic heart disease, cancer and hypertension.

B -Localized physical assessment of the wound by the Southampton Wound assessment scale (Baileyet al., 1992)

Southampton scale was aimed to assessment of the wound infection postoperative. The wound was graded before discharge and after 10 - 14 days postoperatively into one of four categories: normal healing, minor complication, wound infection, and major haematoma.

Scoring system

Each item was observed, categorized, and scored into either present $=1$ or not present $=$ zero on all items of Southampton scoring system.

Tool (II): Assessment of risk factors leading to wound infection (Annex II):

This tool was developed by the researcher based on literature review to assess patients for risk factors leading to wound infection which was classified as either general risk factors as; diabetes mellitus, osteoarthritis, obesity, presence of anemia, presence of chronic disease, rheumatoid arthritis, hepatitis B or $\mathrm{C}$, use of prophylactic antibiotic, malnutrition, for females (menstruation during surgery), length of hospital stay, blood transfusion if needed and its reason or local risk factors as; use of suction drain after surgery and its duration, dressing technique, type of fracture, duration of surgery, location of surgery, method of hair removal (razors or clippers ) and type of antiseptic solution used (povidone iodine or chlorohixidine).

Methods:

1-The study setting was assessed for patients flow in orthopedic and trauma department at Assiut university Hospital.

2-A pilot study carried out in April 2018 to test feasibility and practicability of the study tools on 10 $\%$ (10 patients) of sample. It had also provided an estimate of time needed to fill out the tools.

3-At initial interview the researcher introduced herself to initiate line of communication, fill out the questionnaire sheet.

4-Patients were assessed from time of admission in orthopedic and trauma department (tool I part 1).

5-Patients were assessed by use of Southampton scale (48hrs) after surgery and after 2 weeks after discharge from hospital.

6-Vital signs were measured daily until discharge by use` of (tool I part 2).

7-Risk factors leading to orthopedic wound infection were assessed by use (tool II) once at the initial interview.

8-Observation of the dressing technique was done once by use of (tool II).

9-The content validity: the designed tools were judged by a jury of 3 experts from nursing staff from faculty of nursing at Assiut University, and their opinion were elicited regarding the tool format layout, relevance, comprehensiveness and consistency.

10-Data privacy of the patients was ascertained.

11-The purpose and nature of the study was explained. 


\section{Ethical considerations}

1. Research proposal was approved from ethical committee in the faculty of nursing, Assiut University.

2. There is no risk for study patients during application of the research.

3. Informed consent was taken from all patients who were participating in the study.

4. Study patient privacy was considered during collection of data.

5. Study patients had the right to refuse to participate and or withdraw from the study without any rational any time.

\section{Results}

Table (1): Percentage distribution for demographic data of the studied sample $(n=200)$.

\begin{tabular}{|c|c|c|}
\hline Items & N. & $\%$ \\
\hline \multicolumn{3}{|l|}{ Age } \\
\hline 18-28years & 43 & 21.5 \\
\hline 29-39years & 45 & 22.5 \\
\hline 40-50years & 63 & 31.5 \\
\hline More than 50 years. & 49 & 24.5 \\
\hline \multicolumn{3}{|l|}{ Gender } \\
\hline Male & 131 & 65.5 \\
\hline Female & 69 & 34.5 \\
\hline \multicolumn{3}{|l|}{ Educational Level } \\
\hline High education & 7 & 3.5 \\
\hline Secondary school & 40 & 20.0 \\
\hline Read and write & 47 & 23.5 \\
\hline Illiterate & 106 & 53.0 \\
\hline \multicolumn{3}{|l|}{ Occupation } \\
\hline Working & 47 & 23.5 \\
\hline Not working & 153 & 76.5 \\
\hline \multicolumn{3}{|l|}{ Residence } \\
\hline Urban & 10 & 5.0 \\
\hline Rural & 190 & 95.0 \\
\hline
\end{tabular}

(IIA): Physical and medical data of the patient

Table (2): Distribution of the studied sample regarding their medical diagnosis $(n=200)$.

\begin{tabular}{|l|c|c|}
\hline \multicolumn{1}{|c|}{ Diagnosis } & N. & \% \\
\hline Fracture of upper limb & 100 & 50 \\
\hline Fracture of lower limb & 80 & 40 \\
\hline Patients with others diagnosis & 20 & 10 \\
\hline Total & 200 & 100 \\
\hline
\end{tabular}

Table (3): Percentage distribution for body mass index of the studied sample $(n=200)$.

\begin{tabular}{|l|c|c|}
\hline \multicolumn{1}{|c|}{ Body mass index } & N. & \% \\
\hline Low weight $\left(<20 \mathrm{~kg} / \mathrm{m}^{2}\right)$ & 12 & 6.0 \\
\hline Standards level of weight $\left(20<26 \mathrm{~kg} / \mathrm{m}^{2}\right)$ & 106 & 53.0 \\
\hline Over weight $\left(26<30 \mathrm{~kg} / \mathrm{m}^{2}\right)$ & 50 & 25.0 \\
\hline Obese $\left(30<40 \mathrm{~kg} / \mathrm{m}^{2}\right)$ & 29 & 14.5 \\
\hline Morbid obesity $\left(>40 \mathrm{~kg} / \mathrm{m}^{2}\right)$ & 3 & 1.5 \\
\hline
\end{tabular}

Vol , (7) No , (17) June, 2019 
Table (4): Percentage distribution for surgical history of the studied sample $(n=200)$.

\begin{tabular}{|l|c|c|}
\hline \multicolumn{1}{|c|}{ Previous surgical operation } & N. & \% \\
\hline Appendectomy & 4 & 2.0 \\
\hline Cesarean section & 8 & 4.0 \\
\hline Herniectomy & 5 & 2.5 \\
\hline Thyroidectomy & 1 & .5 \\
\hline Previous orthopedic surgery & 1 & .5 \\
\hline Not undergoing any surgical operation & 181 & 90.5 \\
\hline
\end{tabular}

Table (5): percentage distribution for family and previous medical history of the studied sample (n=77)

\begin{tabular}{|c|c|c|}
\hline Family History and previous medical history & N. & $\%$ \\
\hline Asthma & 7 & 3.5 \\
\hline Chronic heart disease & 9 & 4.5 \\
\hline Cancer & 5 & 2.5 \\
\hline \multicolumn{3}{|l|}{ Diabetes } \\
\hline Diabetes Type 1 & 4 & 2.0 \\
\hline Diabetes Type 2 & 36 & 18.0 \\
\hline Total diabetes & 40 & 18.5 \\
\hline \multicolumn{3}{|l|}{ Treatment } \\
\hline Oral hypoglycemia agent & 30 & 15.0 \\
\hline Insulin injection & 10 & 5.0 \\
\hline \multicolumn{3}{|l|}{ Previous Medical History } \\
\hline Hypertension & 10 & 5.0 \\
\hline Vascular disease & 3 & 1.5 \\
\hline Lung disease & 1 & .5 \\
\hline Epilepsy & 2 & 1.0 \\
\hline
\end{tabular}

Part (IIB): Localized physical assessment of the wound by the Southampton wound assessment scale

Table (6): Comparison between studied patients regarding Southampton wound assessment scale before discharge after 2 weeks from discharge for the study sample $(n=200)$

\begin{tabular}{|c|c|c|c|c|c|c|}
\hline \multirow[t]{2}{*}{ Grade } & \multirow{2}{*}{\multicolumn{2}{|c|}{ Wound appearance }} & \multicolumn{2}{|c|}{$\begin{array}{c}\text { Before } \\
\text { discharge } n=200\end{array}$} & \multicolumn{2}{|c|}{ After 2 weeks $n=59$} \\
\hline & & & $\mathbf{N}$ & $\%$ & $\mathbf{N}$ & $\%$ \\
\hline 0 & \multicolumn{2}{|c|}{ Normal healing } & 89 & 44.5 & 25 & 12.5 \\
\hline \multirow[t]{4}{*}{ I } & \multicolumn{2}{|c|}{ Normal healing with mild bruising or erythema } & 52 & 26.5 & 32 & 16 \\
\hline & Ia & Some bruising & 1 & 0.5 & 13 & 6.5 \\
\hline & $\mathrm{Ib}$ & Considerable bruising & 4 & 2.0 & 4 & 2.0 \\
\hline & Ic & Mild erythema & 47 & 23.5 & 15 & 7.5 \\
\hline \multirow[t]{5}{*}{ II } & \multicolumn{2}{|c|}{ Erythema plus other signs of inflammation } & 51 & 25.0 & 0 & 0 \\
\hline & IIa & At one point & 1 & 0.5 & 0 & 0 \\
\hline & $\mathrm{IIb}$ & Around sutures & 26 & 13.0 & 0 & 0 \\
\hline & IIc & Along wound & 17 & 8.5 & 0 & 0 \\
\hline & IId & Around wound & 7 & 3.5 & 0 & 0 \\
\hline \multirow[t]{5}{*}{ III } & \multicolumn{2}{|c|}{ Clear or haemoserous discharge } & 7 & 3.5 & 2 & 1.0 \\
\hline & IIIa & At one point only $(\leq 2 \mathrm{~cm})$ & 1 & 0.5 & 0 & 0 \\
\hline & IIIb & Along wound $(>2 \mathrm{~cm})$ & 4 & 2.0 & 2 & 1.0 \\
\hline & IIIc & Large volume & 0 & 0.0 & 0 & 0 \\
\hline & IIId & Prolonged (> 3 days) & 2 & 1.0 & 0 & 0 \\
\hline \multirow[t]{3}{*}{ IV } & \multicolumn{2}{|l|}{ Pus } & 0 & 0.0 & 0 & 0 \\
\hline & Iva & At one point only $(\leq 2 \mathrm{~cm})$ & 0 & 0.0 & 0 & 0 \\
\hline & $\mathrm{IVb}$ & Along wound $(>2 \mathrm{~cm})$ & 0 & 0.0 & 0 & 0 \\
\hline $\mathrm{V}$ & \multicolumn{2}{|c|}{$\begin{array}{l}\text { Deep or severe wound infection with or without tissue } \\
\text { breakdown; hematoma requiring aspiration }\end{array}$} & 1 & 0.5 & 0 & 0 \\
\hline
\end{tabular}

Vol , (7) No, (17) June, 2019 
Part (III): Assessment of risk factors leading to orthopedic wound infection.

Table (7): Percentage distribution of the studied sample regarding general risk factors and length of hospital stay $(\mathbf{n}=\mathbf{2 0 0})$.

\begin{tabular}{|l|c|c|}
\hline \multicolumn{1}{|c|}{ General risk factors } & N. & \% \\
\hline Diabetes mellitus & 38 & 19.0 \\
\hline Presence of anemia & 109 & 54.5 \\
\hline Presence of other chronic disease & 18 & 9.0 \\
\hline Rheumatoid Arthritis & 2 & 1.0 \\
\hline Hepatitis B or C. & 3 & 1.5 \\
\hline Blood transfusion & 128 & 64.0 \\
\hline Received & 72 & 36 \\
\hline Not received & 195 & 97.5 \\
\hline Use of prophylactic antibiotic & 15 & 21 \\
\hline Menstruation during surgery for females & $10.3950 \pm 7.89625$ \\
\hline $\begin{array}{l}\text { Mean } \pm \text { SD } \\
\text { Length of hospital stay }\end{array}$ \\
\hline
\end{tabular}

Table (8): Percentage distribution of the studied sample regarding local risk factors of orthopedic wound infection $($ no=200)

\begin{tabular}{|c|c|c|}
\hline Local risk factors & $\mathbf{N}$. & $\%$ \\
\hline \multicolumn{3}{|l|}{ Type of fracture } \\
\hline Open fracture & 23 & 11.5 \\
\hline Closed fracture & 177 & 88.5 \\
\hline History of suction drain after surgery & 131 & 65.5 \\
\hline \multicolumn{3}{|l|}{ Device drainage system duration } \\
\hline 1-2days & 129 & 98.4 \\
\hline 3-4day & 2 & 1.6 \\
\hline \multicolumn{3}{|l|}{ Type of drain system } \\
\hline Hemovac drain & 130 & 99.2 \\
\hline Pen rose drain & 1 & 0.1 \\
\hline \multicolumn{3}{|l|}{ Method of hair removal used } \\
\hline Razors & 132 & 66.0 \\
\hline Clippers & 1 & 0.5 \\
\hline Other & 67 & 33.5 \\
\hline \multicolumn{3}{|l|}{ Method of antiseptic solution used } \\
\hline Povidone-iodine & 200 & 100.0 \\
\hline Chlorohixidine & 0 & 0.0 \\
\hline
\end{tabular}

Part (lv): Dressing technique observation checklist.

Table (9): Percentage distribution of health care providers regarding dressing technique of patient with orthopedic surgery $(n=200)$.

\begin{tabular}{|l|c|c|c|c|c|c|}
\hline \multirow{2}{*}{ Items } & \multicolumn{2}{|c|}{ Done correctly } & \multicolumn{2}{c|}{$\begin{array}{c}\text { Done in } \\
\text { correctly }\end{array}$} & \multicolumn{2}{c|}{ Not done } \\
\cline { 2 - 7 } & $\mathbf{N .}$ & $\mathbf{\%}$ & $\mathbf{N}$. & $\mathbf{\%}$ & $\mathbf{N}$. & $\%$ \\
\hline 1. Wash hands & 1 & .5 & 5 & 2.5 & 194 & 97.0 \\
\hline 2. Explain the procedure to patient & 176 & 88.0 & 17 & 8.5 & 7 & 3.5 \\
\hline 3. Provide for patient privacy & 200 & 100.0 & 0 & 0 & 0 & 0 \\
\hline $\begin{array}{l}\text { 4. Loosen the tape on the patient's existing dressing if } \\
\text { the tape is soiled }\end{array}$ & 197 & 98.5 & 3 & 1.5 & 0 & 0 \\
\hline 5. Done clean gloves & 199 & 99.5 & 0 & 0 & 1 & .5 \\
\hline 6. Remove tape and dressing & 191 & 95.5 & 8 & 4.0 & 1 & .5 \\
\hline
\end{tabular}

Vol , (7) No, (17) June, 2019 


\begin{tabular}{|l|c|c|c|c|c|c|}
\hline $\begin{array}{l}\text { 7. Properly dispose of dressing and gloves in plastic } \\
\text { bag }\end{array}$ & 60 & 30.0 & 140 & 70.0 & 0 & 0 \\
\hline 8. Set up sterile field and open sterile supplies & 4 & 2.0 & 193 & 96.5 & 3 & 1.5 \\
\hline 9. Pour cleansing solution into sterile container & 21 & 10.5 & 158 & 79.0 & 21 & 10.5 \\
\hline 10.Properly apply sterile gloves & 19 & 9.5 & 6 & 3.0 & 175 & 87.5 \\
\hline 11. Inspect wound & 187 & 93.5 & 11 & 5.5 & 2 & 1.0 \\
\hline 12. Cleansing wound in the right way & 34 & 17.0 & 166 & 83.0 & 0 & 0 \\
\hline $\begin{array}{l}\text { 13. Use one gauze square for each wipe discarding it } \\
\text { in plastic bag }\end{array}$ & 20 & 10.0 & 178 & 89.0 & 2 & 1.0 \\
\hline $\begin{array}{l}\text { 14. Clean around drain moving from center outward } \\
\text { in a circular motion }\end{array}$ & 106 & 53.0 & 40 & 20.0 & 54 & 27.0 \\
\hline 15. Drying wound correctly & 106 & 53.0 & 40 & 20.0 & 54 & 27.0 \\
\hline 16.Apply antibiotic ointment if ordered & 38 & 19.0 & 1 & .5 & 161 & 80.5 \\
\hline 17. Apply dry sterile dressing & 198 & 99.0 & 0 & 0 & 2 & 1.0 \\
\hline 18. Secure dressing with tape & 200 & 100.0 & 0 & 0 & 0 & 0 \\
\hline $\begin{array}{l}\text { 19. Remove and properly dispose of sterile gloves and } \\
\text { all supplies }\end{array}$ & 46 & 23.0 & 143 & 71.5 & 11 & 5.5 \\
\hline 20. Wash hands & 2 & 1.0 & 0 & 0 & 198 & 99.0 \\
\hline 21. Documentation & 0 & 0 & 0 & 0 & 200 & 100.0 \\
\hline
\end{tabular}

Table (1): Revealed that the highest percentage of the studied sample were males $65.5 \%$, Illiterate $53 \%$, Not working $76.5 \%$, and $95 \%$ living in rural area, while regarding age $31 \%$ of studied sample, their age range from 40 to 50 years.

Table (2): Revealed that $(50 \%)$ of the studied sample were diagnosed with fracture of upper limb, (40\%) were having fracture of lower limb, (10\%) were diagnosed other than that.

Table (3): Showed that the majority of the studied sample was having a standard body weight $53 \%$, while $25 \%$ of them were overweight and $14.5 \%$ were obese.

Table (4): Showed that regarding surgical history of the studied sample $90.5 \%$ of them did not undergoing any previous surgery, and $9.5 \%$ of them underwent surgery; $4 \%$ of them cesarean section and $2 \%$ appendectomy while $2.5 \%$ of them had herniectomy.

Table (5): Illustrated that regarding family history of the studied patients $18.5 \%$ of them were having diabetes, $15 \%$ were treated by oral hypoglycemic agents, $5 \%$ were having hypertension and $1.5 \%$ were having a vascular disease.

Table (6): Revealed that regarding assessment of the studied sample wound by using of the Southampton Wound assessment scale; $44.5 \%$ were having normal wound healing, $26.5 \%$ were having a normal wound with mild bruising or erythema, $25 \%$ were having erythema plus other signs of inflammation, regarding assessment of the studied patients after discharge $12.5 \%$ were having normal wound healing, $16 \%$ were having a normal wound with mild bruising or erythema.
Table (7): Showed that regarding general risk factors of the studied patients; $19 \%$ were having diabetes mellitus, $54.5 \%$ were suffering from anemia, $64 \%$ received blood transfusion, $9 \%$ were having a chronic disease, the majority of them $97.5 \%$ received a prophylactic antibiotic and $21 \%$ were having menstruation during surgery for females, while regarding to length of hospital stay Mean \pm SD were $10.3950 \pm 7.89625$.

Table (8): Illustrated that regarding local risk factors of the studied patients; $88.5 \%$ were have closed fracture, $65.5 \%$ were having a suction drain after surgery, as regarding to type of drain used after surgery $99.2 \%$ used hemovac drain, $66 \%$ of patients razors were used for hair removal and povidone iodine was used as antiseptic solution for all patients.

Table (9): Revealed that regarding dressing technique observation checklist $97 \%$ of health care providers do not practice hand washing before dressing, $87.5 \%$ do not apply sterile gloves before dressing, $80.5 \%$ do not apply antibiotic ointment after dressing, $99 \%$ of them do not practice hand washing after dressing and $100 \%$ of them do not document any data relevant to dressing technique following the procedure.

\section{Discussion}

Orthopedic wound infections are one of the common causes of high morbidity and are difficult to treat due to the use of implants for open reduction and internal fixation which are foreign bodies to the body, orthopedic wound are at an increased risk of 
microbiological contamination and infection (Vishwajith et al., 2014).

The aim of this study was to assess the prevalence and risk factors leading to orthopedic wound infection at Assiut University Hospital. Incidence of orthopedic wound infection at Assiut University Hospital over the past three months from May to July of the year 2018 was more than quarter of the studied sample was have orthopedic wound infection.

The current study revealed that; more than half of studied patients were males, illiterate, living in rural area and their age group ranged from more than forty to less than fifty years old, this current study result finding was in line with Dr. KrishanY 2015., (Herode et al., 2016) who conducted the study of incidence of post-operative wound infection in orthopedic surgery in Brazil, and who reported that more than half of the studied patients whose age group ranged from 41-50 age years

The present study revealed that; Half of the studied sample were having fracture of upper limb, near half of the studied sample were having fracture of lower limb and ten percent were having diagnoses other than these, this result comes in disagreement with (Tamam, 2016), who conducted the study of prevalence and predisposing factors of compartment syndrome among traumatic patients inAssiut University, Hospital, who found that nearly third of the sample included in their study were having tibial plateau fracture.

The present study revealed that; there was a highly statistically significant difference between vital signs and wound infection, this result agree with (Hashem, 2018), who conducted the study of effect of designing nursing guideline on minimizing postoperative complication for patients undergoing thyroidectomy Assiut University, who reported that vital signs are a mechanism to universally communicate a patient's condition and severity of their disease. Regarding body mass index there was a positive correlation between body mass index and wound infection this result agree with (Namba et al., 2013), who conducted the study of risk factors associated with deep surgical site infections after primary total knee arthroplasty, who found that deep surgical site infections (SSIs) after primary total knee arthroplasty had high incidence with large body mass index (BMI) (i.e. Obesity). (Panahi et al., 2012), who conducted the study of operating room traffic is a major concern during total joint arthroplasty in India, who reported that BMI of greater than $40 \mathrm{~kg} \backslash \mathrm{m} 2$ is considered a risk factor for periprosthetic joint infection (PJI).

Regarding glucose level; mean of the studied patients was $7.08 \mathrm{mmol}$. This result agreed with (Rutan \&
Sommers, 2012), who conducted the study of hyperglycemia as a risk factor in the perioperative patient in India, who reported that there is an association between hyperglycemia and exposure to surgical intervention, regardless if the patient is diabetic or not, which in turn impairs the wound healing process and subsequently increases the risk of SSI.

Regarding to assessment of the wound by use of southampton wound assessment scale, the present study illustrated that nearly half of the studied patients were having normal healing, nearly quarter of the studied patients were having normal healing with mild bruising or erythema, quarter of the studied patients were having erythema plus other signs of inflammation, about three and a half percent of the studied patient were having clear or haemoserous discharge and no case was having pus or deep or severe wound infection with or without tissue breakdown or hematoma requiring aspiration. This result comes in agreement with (TerGunne et al., 2010), who conducted the study of incidence of surgical site infection following adult spinal deformity surgery, an analysis of patient risk in european, who reported that the majority of cases were having SSI.

On other hand, when subsequently the patients were followed up after two weeks from discharge, nearly all patients were having normal healing, and normal healing with mild bruising or erythema. In this regard, (Alam et al., 2014), who conducted the study of Surgical Site Infection; frequency after open cholecystectomy using southamptom wound scoring system in surgical unit khyber teaching hospital Poshawar, who stressed that strict follow up protocol in outpatient clinic and patient education can significantly decrease the incidence of surgical site infections.

The present study showed that; about one fifth of the studied patient were having diabetes mellitus, this result agree with (Gheiti and Mulhall, 2013), who conducted the study of Peri-Prosthetic joint infection: prevention, diagnosis and management, who reported that elevated blood glucose level is a predisposing factor of periprosthetic joint infection. Regarding chronic diseases the present study showed that about nine percent were having chronic diseases, this result is in line with (Namba et al., 2013), who conducted the study of Risk factors associated with deep surgical site infections after primary total knee arthroplasty, who found that the risk of deep SSIs after primary total knee arthroplasty would increase with diabetes. Similarly, (Daines et al., 2015) have reported diabetes as a risk factor for Periprosthetic joint infection. 
The present study illustrate that; the majority of the studied patients received prophylactic antibiotic every day postoperatively until discharge from hospital, this result disagree with (Gheiti \& Mulhall, 2013) who recommended that antibiotic prophylaxis should not exceed the first day postoperatively.

Regarding length of hospital stay; the present study showed that there was a positive correlation between length of hospital stay and wound infection, this result is supported by (Tichansky et al., 2011), who conducted the study of The SAGES Manual of Quality, Outcomes and Patient Safety. Springer Science \&Business Media, who found that admission to the hospital within the same day of surgery is associated with a low risk of SSI, (Pulido et al., 2008), who conducted the study of Periprosthetic joint infection the incidence, timing and predisposing factors, who declared that as the patient's hospital stay is prolonged, the patient will be more exposed to nosocomial microorganisms that may result in orthopedic SSI.

The present study showed that; more than half of the studied patients were having anemia, this result agree with (Greenky et al., 2012), who revealed that the presence of anemia preoperatively is an independent risk factor for PJI by increasing the risk of PJI, which in turn causing failure in arthroplasty surgery. Regarding blood transfusion; the present study illustrated that more than three fifths of the studied patients received blood transfusion.

This result agree with (Olsen et al., 2008) who conducted the study of Surgical site infection following orthopedic spinal operation in American society of health system, who identified perioperative transfusion of packed red blood cells and platelets as a factor increasing the risk of SSIs of orthopedic operations and agree with (Sidhwa \& Itani, 2015) who reported that blood transfusion has been found to enhance inflammation and to suppress immunity, and immunomodulation occurs in relation to the transfused blood, thereby increasing the risk of nosocomial infection and primarily surgical site infections.

The present study also revealed that; the highest percent of the studied patients had suction drain after surgery (Hemovac drain) for a period one to two days, this result disagree with (Olsen et al., 2008) who conducted the study of Risk factors for surgical site infection following orthopedic spinal operations in American society of health system, who identified the use of drain for three days or more postoperatively as a factor to increase the risk of SSIs after orthopedic operations.

The present study found that; razors were used for hair removal in more than three fifths of the studied patients, this result contradicts the results by (Owens \& Stoessel, 2008), who conducted the study of Surgical site infection epidemiology, microbiology and prevention, who reported that clippers should be used instead of shaving if hair removal is necessary in order to prevent microscopic cuts in the skin that act as foci for infection.

Regarding to the antiseptic solution which was used; the present study found that povidone - iodine was the used solution in all of the studied group patients. This result comes in disagreement with (Macias et al., 2013) who conducted the study of Chlorhexidine is a better antiseptic than povidone iodine and sodium hypochlorite because of its substantive effect American, who identified the use of povidoneiodine to prepare the skin as a predictor of SSIs, providing the fact that povidone-iodine has a short activity when compared to chlorohixidineand, it can be inactivated by serum proteins and blood this results also disagree with (Lachapelle et al., 2013) who conducted the study of Antiseptics in the era of bacterial resistance: a focus on povidone iodine, who reported that Chlorhexidine-alcohol is better than povidone-iodine in preventing SSIs when used to cleanse surgical sites.

The present study showed that; mean duration of surgery in the studied patients were more than two and half hours, this result disagree with (Beldi et al., 2009) who conducted the study of Impact of intraoperative behavior on surgical site infections, who identified a long surgical procedure lasting more than three hours as a risk factor for developing SSIs.

The present study results illustrated that; there was a negative correlation between dressing technique and wound infection, the majority of the health care providers did not apply hand washing before dressing, did not apply sterile gloves before dressing, did not apply antibiotic ointment after dressing, and nearly all of them did not perform hand washing after dressing and all of them did not document any pertinent data related to the wound after dressing, this result comes in agreement with (Ruszczak et al., 2013) who conducted the study of Comparative evaluation of silver-containing antimicrobial dressings and drugs, who declared that a good dressing should maintain a moist wound environment and thus promote wound healing, be able to remove excessive exudate that might lead to maceration of the wound, and provide a good barrier against bacterial or fluid contamination.

\section{Conclusion \& Recommendations Conclusion}

According to the result of this present study, Prevalence of orthopedic wound infection at Assiut 
University Hospital over the past three months from May to July of the year of 2018 was 57 patients out of 200 patients admitted to orthopedic and trauma department.

There was a positive correlation between vital signs and wound infection of the studied patients ( $\mathrm{p}$ value.001) that present of wound infection affects the wound vital signs (body temperature, pulse, and respiration).

Regarding risk factors of the studied patients; the majority of the study patient were suffering from anemia, received a prophylactic antibiotic, having diabetes mellitus, having suction drain during surgery and having menstruation during surgery for females.

Regarding length of hospital stay the present study showed that; there was a positive correlation ( $p$ value 0.001 ) between length of hospital stay and wound infection, orthopedic wound infection prolonged hospital stay that lead to increase cost and decrease patient quality of life.

Based on the result of the present study, it can concluded that regarding dressing technique there was a negative correlation ( $\mathrm{p}$ - value 0.017 ) between dressing technique and wound infection so nurses should educated to apply strict sterile dressing technique that lead to decrease development of wound infection.

\section{Recommendations}

In the light of the findings of the current study the following recommendations were suggested:-

1. It is important to identify risk factors for orthopedic surgical site infections so that appropriate prevention strategies can be implemented.

2. Nurses must receive adequate knowledge about signs and symptoms of orthopedic wound infection for early detection and proper management of wound infection.

3. Increase the awareness of nurses through attending scientific meeting and conferences and to keep them pace with the rapidly growing wealth of knowledge and practice.

4. It is important to use aseptic technique during wound dressing.

\section{References}

1. Alem S., Khan M., GulAandJan Q., (2014): Surgical Site Infection; frequency after Open Cholecystectomy Using Southamptom Wound Scoring System in Surgical Unit Khyber Teaching Hospital Poshawar, Professional Medical Joural,Vol.(21),N.(2), PP.377-381.

2. Bailey I., Karran S., Toyn K., Brough P., Ranaboldo C., \& Karran S., (1992): Community surveillance of complications after hernia surgery. BMJ, vol. (30), NO. (4) p.p.46971.

3. Barrack R., \& Harris W., (2013): The value of aspiration of the hip joint before revision to hip arthroplasty J Bone Joint Surg AM, vol.(7), NO.(5), p.p.66-76.

4. Baron, E., Miller, J., Weinstein, M., Richter, S., Gilligan, P., Thomson J., \& RobinsonDunn, B., (2013): A guide to utilization of the microbiology laboratory for diagnosis of infectious diseases recommendations by the Infectious Diseases Society of America (IDSA) and the American Society for Microbiology (ASM) a. Clinical infectious diseases,vol.(57), NO.(4), PP.22-121.

5. Bratzler, D., Dellinger, E., Olsen, K., Perl, T., Auwaerter, P., Bolon, M., \& Steinberg, J., (2013): Clinical practice guidelines for antimicrobial prophylaxis in surgery. Surgical infections,vol.(14), NO.(1),PP. 73-156.

6. Blood, A., Sandoval, M., Burger, E., \& Halverson-Carpenter, K., (2017): Risk and protective factors associated with surgical infections among spine patients. Surgical infections, vol.(18), NO.(3),PP. 234-249.

7. Daines B., Dennis D., \& Amann S., (2015): InfectionPrevention in Total Knee Arthroplasty. J Am AcadOrthopSurg 23: 356364.

8. Gheiti A., \& Mulhall K., (2013): PeriProsthetic Joint Infection: Prevention, Diagnosis and Management INTECH AMJ sur, vol. (19), NO.(8), PP.157-162.

9. Greenky M., Gandhi K., \& Pulido L., (2012): Preoperative anemia in total joint arthroplasty: is it associated with periprosthetic joint infection?. ClinOrthop, vol. (47), NO. (3), PP. 2695 - 2701.

10. Hashem E., (2018): Effect of Designing Nursing Guideline on minimizing postoperative complication for patients undergoing thyroidectomy master degree Assiut University Faculty of Nursing pp.44

11. Herode G., Shroff A., Nair V., Yadav K., \& Patel M., (2016): A study of incidence of postoperative wound infection in orthopaedics surgery at a tertiary care center. J Pharm Biomed Sci, vol. (6), NO. (1), P.59-61.

12. Husebye E., Lybery T., Opdahl H., Aspelin R., Stoen R., \& Madsen J., (2012): Intramedullary nailing of femoral shaft fractures in poly traumatized patients scand $\mathrm{J}$ trauma, vol. (20), NO.(2), p.p46-47

13. Huttunen, R., \& Syrjänen, J., (2013): Obesity and the risk and outcome of infection. 
International journal of obesity, vol.(37), NO.(3), PP.333.

14. Korol, E., Johnston, K., Waser, N., Sifakis, F., Jafri, H., \& Kyaw, M., (2013): A systematic review of risk factors associated with surgical site infections among surgical patients. PloS one, vol.(8), NO.(12), PP.74-83

15. Lachapelle M., Castel O., Casado F., Leroy B., Micali G., Tennstedt D., \& Lambert J., (2013): Antiseptics in the era of bacterial resistance: a focus on povidone iodine $\mathrm{J}$ A M Acadorthopsurg, vol.(3), NO.(2),PP.160-166.

16. Namba S., Inacio C., \& Paxton E., (2013): Risk factors associated with deep surgical site infections after primary total knee

arthroplasty. J Bone Joint Surg Br, vol. (9), NO. (5), PP.775-782

17. Panahi P., Stroh M., Casper S., (2012): Operating room traffic is a major concern during total joint arthroplasty. ClinOrthop, vol. (47), pp. 2690-2694

18. Ruszczak Z., Schwartz R., Joss-Wichman E., Wichman R., \& Zalewska A., (2013): Comparative evaluation of silver-containing antimicrobial dressings and drugs. International wound journal, vol. (4), NO. (2), PP. 114-122.

19. Rutan L., \& Sommers K., (2012): Hyperglycemia as a risk Factor in the perioperative patient. J, vol. (9), NO. (5), PP.352-364.

20. Santos M., Teixeria R., Augustofilho D., (2010): Surgical site infections in adultspatients undergoing of clean and contaminated surgeries at auniversity Brazilian hospital Arg Gastroenterol, vol. (47). NO. (4), PP.6-10

21. Shrestha, G., \& Thapa, B., (2018): Knowledge and Practice on Infection Prevention among Nurses of Bir Hospital, Kathmandu. Journal of Nepal Health Research Council, vol. (16), NO.(3), PP.330-335.

22. Sidhwa F., \& Itani K., (2015): Skin preparation before surgery: options and evidence. Surgical infections,vol. (16), NO.(1), PP.14-23.

23. Tamam M., (2016): Prevalence and predisposing factors of compartment syndrome among traumatic patients master degree at Assiut University, Hospital Faculty of nursing pp. 45

24. TerGunne A., Van Laarhoven C., \& Cohen D., (2010): Incidence of surgical site infection following adult spinal deformity surgery, an analysis of patient risk. European Spine Journal, vol.(19), NO.(6), PP.982-988.

25. Tichansky D., Morton J., \& Jones D., (2011): The SAGES Manual of Quality,
Outcomes and Patient Safety. Springer Science \&BusinessMedia, vol.(209), NO.(6), PP.49-59

26. Tong S., Davis J., Eichenberger, E., Holland T., \& Fowler V., (2015): Staphylococcus aureus infections: epidemiology, pathophysiology, clinical manifestations, and management. Clinical microbiology reviews, vol. (28), NO. (3), PP. 603-661.

27. Vishwajith Y., Anuradha K., \& Venkatesha D., (2014): Evaluation of aerobic bacterial isolates and its drug susceptibility pattern in orthopedic infections, vol.(2), NO.(6), PP.12561262. 